\title{
Corrigendum to "Air-sea exchange and gas-particle partitioning of polycyclic aromatic hydrocarbons in the Mediterranean" published in Atmos. Chem. Phys., 14, 8905-8915, 2014
}

\author{
M. D. Mulder ${ }^{1}$, A. Heil ${ }^{2, *}$, P. Kukučka ${ }^{1}$, J. Klánová ${ }^{1}$, J. Kuta ${ }^{1}$, R. Prokeš ${ }^{1}$, F. Sprovieri ${ }^{3}$, and G. Lammel ${ }^{1,4}$ \\ ${ }^{1}$ Masaryk University, Research Centre for Toxic Compounds in the Environment, Brno, Czech Republic \\ ${ }^{2}$ Helmholtz Research Centre Jülich, Institute for Energy \& Climate Research, Jülich, Germany \\ ${ }^{3}$ CNR, Institute for Atmospheric Pollution Research, Rende, Italy \\ ${ }^{4}$ Max Planck Institute for Chemistry, Mainz, Germany \\ * now at: Max Planck Institute for Chemistry, Mainz, Germany
}

Correspondence to: G. Lammel (lammel@recetox.muni.cz)

Figure 2 in Sect. 3.3 on p. 8912 did not show a colour bar and the two maps were erroneously swapped. The correct figure is shown here.
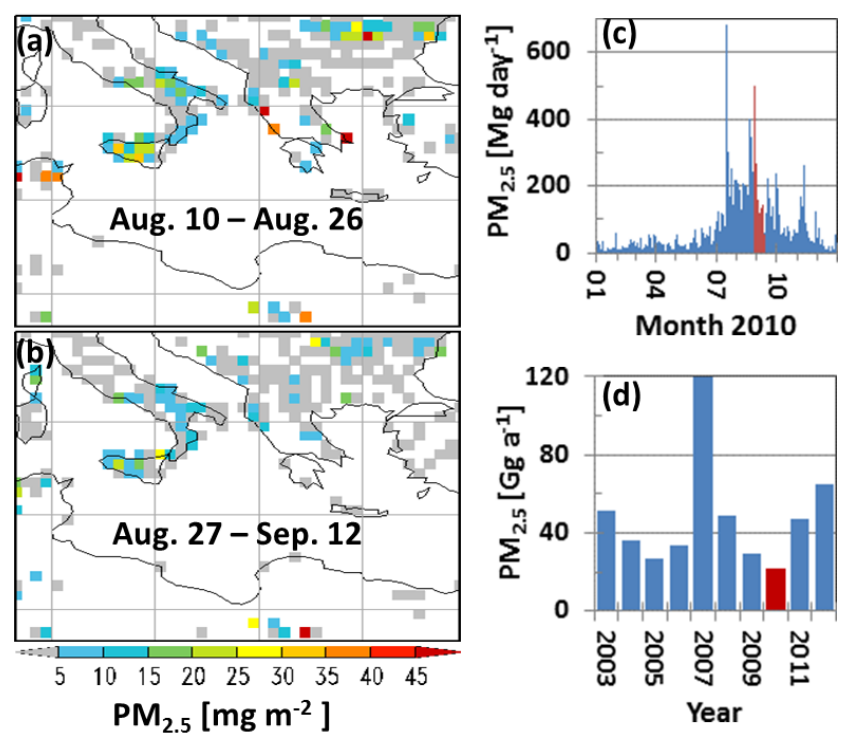

Figure 2. Spatial pattern of fire-related $\mathrm{PM}_{2.5}$ emissions (Global Fire Assimilation System GFASv1.0; Kaiser et al., 2012) for the East Mediterranean $\left(28-45^{\circ} \mathrm{N} / 8-30^{\circ} \mathrm{E}\right)$, (a) time integral of 10-26 August, (b) time integral of 27 August-12 September 2010, given as sum over each period in $\mathrm{mg} \mathrm{m}^{-2}$. Areas with no observed fire activity are displayed in white. Temporal pattern of domainintegrated (c) daily total $\mathrm{PM}_{2.5}$ emissions over 2010 and (d) yearly total $\mathrm{PM}_{2.5}$ emissions over 2003 to 2012. Labelled in red is (c) the period of the Urania cruise (27 August-11 September 2010) (d) and the year 2010 . 